\title{
Race, Reality and the Road to Redemption: COVID-19's Precipitous Pandemic Problem among Black Lives that Matter
}

\author{
Eric Rogers*
}

Profess or Psychology, physics educator, Chicago, Illinois, UK

*Corresponding author: Eric Rogers, Profess or Psychology, physics educator, Chicago, Illinois, UK

\begin{abstract}
Race and ethnicity and socioeconomics are high and heinous risky punitive pawns in game of life and health care relative to underlying conditions that impact health. Long-standing systemic health and social inequities open the door and maintain a breeze of devastating consequences putting many people from racial and ethnic minority groups at increased risk of getting sick and dying from COVID-19. The term "racial and ethnic minority groups" includes people of color with a wide variety of backgrounds and experiences. Equally important, But some experiences are common to many people within these groups (heart disease, dementia, alzheimers, diabetes, stroke, etc.). Yet, specific social determining factors wreak havoc on individuals, particularly of color: Social determinants are simply are conditions in the places where people live, learn, work, and play that affect a wide range of health and quality-of life-risks and outcomes.
\end{abstract}

\section{Introduction}

The bottom line is that social determinants of health have historically prevented them from having fair opportunities for economic, physical, and emotional health. Furthermore, there is unequivocal evidence that some racial and ethnic minority groups are being disproportionately affected by COVID-19. Factors that contribute to increased risk include but not limited to : Ignorance and Irresponsiblity: Individuals across the racial divide in America often believe they are invincible and immune to the virus, etc. They consciously choose not to wear mask nor keep their respective distances 6 feet or further. Hygiene is not taken seriously nor health efforts to minimize the spread and contagiousness of COVID 19. Far too many persons take solace in having house parties, cookouts, barbecues, backyard fellowships and birthday partiesall of course with either limited masking, distance or essentially none at all. Discrimination: Unfortunately, discrimination exists in systems meant to protect well-being or health. Discriminating systems include health care, housing, education, criminal justice, and finance. Make no mistake about it, discrimination in any form which includes racism, can lead to chronic and toxic stress and shapes social and economic factors that put some people from racial and ethnic minority groups at increased risk for COVIDHealthcare access and utilization: People of color and lower income backgrounds are more likely to be uninsured than nonHispanic whites. An injury and insult is the reality of many other factors, such as lack of transportation, child care, or ability to take time off of work; communication and language barriers; cultural differences between patients and providers; and historical and current discrimination in healthcare systems. Many people of color don't trust the healthcare system and they shouldn't. Why? Because life is a cruel teacher: It gives you exam first, then the lesson (Table 1). The historical realities of exploitation, abuse, degradation and death specifically targeted at people of color are a matte of public and private records such as the Tuskegee Study of Untreated Syphilis in the African American Male and sterilization without people's permission highlight this reality.

Occupation: People of color are grossly represented in work settings such as healthcare facilities, farms, factories, grocery stores, house keeping, cleaning, and public transportation. Some people who work in these settings have more chances to be exposed to the virus that causes COVID-19 due to several factors, such as close 
contact with the public or other workers, not being able to work from home, and not having paid sick days. Educational, income, and wealth gaps: Inequities in access to high-quality education for some racial and ethnic minority groups can lead to lower high school completion rates and barriers to college entrance. This may limit future job options and lead to lower paying or less stable jobs [1].
People with limited job options likely have less flexibility to leave jobs that may put them at a higher risk of exposure to the virus that causes COVID-19. People in these situations often cannot afford to miss work, even if they're sick, because they do not have enough money saved up for essential items like food and other important living needs.

Table 1: The statistics are grim.

\begin{tabular}{|c|c|c|c|c|}
\hline $\begin{array}{l}\text { Rate ratios compared } \\
\text { to White, Non-Hispanic } \\
\text { Persons }\end{array}$ & $\begin{array}{l}\text { American Indian or } \\
\text { Alaska Native, Non- } \\
\text { Hispanic persons }\end{array}$ & $\begin{array}{l}\text { Asian, Non-Hispanic } \\
\text { persons }\end{array}$ & $\begin{array}{c}\text { Black or African } \\
\text { American, Non-Hispanic } \\
\text { persons }\end{array}$ & $\begin{array}{c}\text { Hispanic or Latino } \\
\text { persons }\end{array}$ \\
\hline Cases1 & 2.8x higher & 1.1xhigher & 2.6x higher & 2.8xhigher \\
\hline Hospitalization2 & 5.3xhigher & 1.3xhigher & 4.7xhigher & 4.6xhigher \\
\hline Death3 & 1.4xhigher & No higher & 2.1xhigher & 1.1xhigher \\
\hline
\end{tabular}

Housing: Some people from racial and ethnic minority groups live in crowded conditions that make it more challenging to follow prevention strategies. In some cultures, it is common for family members of many generations to live in one household. In addition, growing and disproportionate unemployment rates for some racial and ethnic minority groups during the COVID-19 pandemic may lead to greater risk of eviction and homelessness or sharing of housing. These factors and others are all associated with more COVID-19 cases, hospitalizations, and deaths in areas where racial and ethnic minority groups live, learn, work, play, and worship. They have also contributed to higher rates of specific medical illnesses and conditions that increase one's risk of severe illness from COVID-19. In addition, community strategies to slow the spread of COVID-19 may cause unintentional harm, such as lost wages, reduced access to services, and increased stress, for some racial and ethnic minority groups [2-4].

Furthermore, neuro-cognitive implications are meticulously decisive in their impact and impetus effects: Whether it is mental fatigue and mild loss of concentration major neuro health issues are frequently reported by people with COVID-19. More severe cognitive impairment is reported in those with secondary illness such as stroke, which has been reported even in younger COVID patients and is believed to result from coagulopathy caused by SARS-CoV-2. Encephalopathy is observed after extubating, possibly due to lingering effects of sedation and possibly due to the effects of mechanical ventilation. This often resolves over a period of days but can sometimes persist for weeks or even months.

\section{Conclusion}

Encephalopathy can be further exacerbated by bacterial infection, which can develop during ventilation. So far there are relatively few reports of meningitis/encephalitis associated with SARS-CoV-2, although it is possible more reports of direct infection will emerge over time, similar to previous coronavirus outbreaks (e.g., the SARS-CoV-1 outbreak in 2003 and the Middle East Respiratory Syndrome outbreak in 2012) And the most recent medical and scientific reports showed that the most severe cases of COVID-19 were the most likely to develop neurological symptoms [4-8]. Risk factors for neurocognitive symptoms in those cases are similar to other populations with acute respiratory distress syndrome. Those risk factors include pre-existing diagnoses such as dementia, subarachnoid hemorrhage, and epilepsy. Increased risk of neurocognitive effects is also associated with pathophysiological events during acute care, such as hypoxemia, hypoperfusion and inflammatory response. Finally, further increase in risk is observed when management during acute care includes sedation, mechanical ventilation, and complications such as delirium. Consequently, we have been warned. Wear your mask. Wash your hands. Wedge the distance (whether its 6 feet or 6 steps)...because this virus...this vicious and vile venom of bio-chemical expression is coming soon to a place..... person and/or a predicament near you.

\section{References}

1. Institute of Medicine (US) Committee on the Consequences of Uninsurance. Care Without Coverage: Too Little, Too Late. Washington (DC): National Academies Press (US).

2. Institute of Medicine (2003) Unequal Treatment: Confronting Racial and Ethnic Disparities in Health Care. Washington, DC: The National Academies Press, USA.

3. (2003) US National Library of Medicine. Native Voices: Timeline: Government admits forced sterilization of Indian Women.

4. Novak NL, Lira N, O'Connor KE, Harlow SD, Kardia SLR, et al. (2018) Disproportionate Sterilization of Latinos Under California's Eugenic Sterilization Program, 1920-1945. Am J Public Health 108(5): 611-613.

5. Stern AM (2005) Sterilized in the name of public health: race, immigration, and reproductive control in modern California. Am J Public Health 95(7): 1128-1138.

6. Prather C, Fuller TR, Jeffries WL (2018) Racism, African American Women, and Their Sexual and Reproductive Health: A Review of Historical and Contemporary Evidence and Implications for Health Equity. Health Equity 2(1): 249-259.

7. US Bureau of Labor Statistics. Labor force characteristics by race and ethnicity.

8. Economic Policy Institute. Black workers face two of the most lethal preexisting conditions for coronavirus-racism and economic inequality. 
(C) (P) This work is licensed under Creative

To Submit Your Article Click Here: Submit Article

DOI: $10.32474 /$ SJPBS.2020.04.000191

\begin{tabular}{|c|c|}
\hline SJPBS & $\begin{array}{l}\text { Scholarly Journal of Psychology } \\
\text { and Behavioral Sciences }\end{array}$ \\
\hline & $\begin{array}{l}\text { Assets of Publishing with us } \\
\text { - Global archiving of articles } \\
\text { - Immediate, unrestricted online access } \\
\text { - Rigorous Peer Review Process }\end{array}$ \\
\hline $\begin{array}{l}\text { Scholarly Journal of } \\
\text { Pschology \& Behavioral sciences }\end{array}$ & $\begin{array}{l}\text { - Authors Retain Copyrights } \\
\text { - Unique DOI for all articles }\end{array}$ \\
\hline
\end{tabular}

